\title{
Synthesis and structural properties characterization of ha/alumina and ha/mgo nanocomposite for biomedical applications
}

\begin{abstract}
$\mathrm{HA} /$ Alumina and $\mathrm{HA} / \mathrm{MgO}$ nanocomposites were successfully prepared by using the hydrothermal method for the first time at $250^{\circ} \mathrm{C}$. The mechanisms of composite formation, crystallite size, crystallinity, morphology, were studied HA/Alumina and $\mathrm{HA} / \mathrm{MgO}$ nanocomposites. XRD and FTIR investigations showed an intermolecular interaction between $\mathrm{HA} / \mathrm{Alumina}$ and $\mathrm{HA} / \mathrm{MgO}$. The formation of $\mathrm{HA} / \mathrm{Alumina}$ and $\mathrm{HA} / \mathrm{MgO}$ nanocomposites are polycrystalline in nature. It confirmed in TEM analysis. TEM images further ascertained that $\mathrm{HA}_{\mathrm{p}}$ /Alumina was formed in a short nanorod shape and $\mathrm{HA} / \mathrm{MgO}$ nanocomposites show nanocluster like morphology. The FTIR measurement shows the appropriate vibrational spectra of $\mathrm{HA} / \mathrm{Alumina}$ and $\mathrm{HA} / \mathrm{MgO}$ nanocomposites. The UV-VIS measurements show the band-gap of HA/Alumina and $\mathrm{HA} / \mathrm{MgO}$ nanocomposites. This study provides a platform for further research on the $\mathrm{HA} /$ Alumina and $\mathrm{HA} / \mathrm{MgO}$ nanocomposites for biomedical applications.
\end{abstract}

Volume I Issue 4 - 2017

\author{
Vijayalakshmi V \\ Department of Physics, Erode Sengunthar Engineering College, \\ India
}

Correspondence: Vijayalakshmi V, Crystal Growth Laboratory, Department of Physics, Erode Sengunthar Engineering College, Erode-638057, India, Email vijiphysics007@gmail.com

Received: November 18, 2017 | Published: December 07, 2017

Keywords: hydrothermal method, nanocomposites, hydroxyapatite, alumina, mgo, tem, $\mathrm{x}$-ray diffraction

\section{Introduction}

HA- Alumina nanocomposite is biocompatible and has desirable mechanical and physical properties. Less cost, simple synthesis method, and fast production are the added advantages of this nanocomposite. Thus HA coatings on the surface of alumina substrates are used to combine excellent bioactivity of HA with superior mechanical properties of the alumina substrates. One of the elements associated with biological apatite is magnesium. ${ }^{1} \mathrm{Mg}$ incorporation into $\mathrm{HA}_{\mathrm{p}}$ stimulates osteoblast proliferation. $\mathrm{Mg}$ acts similar to a growth factor during the early stages of osteogenesis and promotes bone formation. Typical concentrations of carbonate and $\mathrm{Mg}$ ions in human bone are 5.8 and $0.55 \mathrm{wt} \%$, respectively. Although the extent of these elemental substitutions is minimal, they are important for biological activity and interaction between bone mineral and calcium-phosphate-based implant materials by influencing crystal growth, dissolution rate, solubility, surface chemistry and charge, morphology, and the mechanical properties. By substitution of a smaller $\mathrm{Mg}$ ion or $\mathrm{Al}$ ion for a larger $\mathrm{Ca}$ ion, additional structural changes may be required to prevent destabilization/decomposition of the structure during heat treatment process. This can be achieved by co-substitution of a second ion, to the HA structure. ${ }^{2}$ Thus, $\mathrm{MgO}$ and Alumina nanoparticles dispersed within polymer composites have the potential to enhance bone tissue formation with limited adverse degradation reactions. Taking advantage of these prior studies, the objective of the present in vitro study was to characterize $\mathrm{MgO}$ and Alumina nanoparticles as additive materials for orthopedic tissue engineering applications, especially when used in combination with HA nanoparticles. ${ }^{3}$

\section{Materials}

$\mathrm{HA} /$ Alumina and $\mathrm{HA}_{\mathrm{p}} / \mathrm{MgO}$ nanocomposites were prepared using novel environmentally benign technology called hydrothermal method. The following precursors were used for the preparation of nanocomposite. Calcium Nitrate $\left(\mathrm{Ca}\left(\mathrm{NO}_{3}\right)_{2} \cdot 4 \mathrm{H}_{2} \mathrm{O}\right.$, Merc $\left.\mathrm{GR}, 99 \%\right)$ is taken as the Calcium precursor. Diammonium Hydrogen Phosphate $\left(\mathrm{NH}_{4} \mathrm{HPO}_{4}\right.$, Merck GR, 99\%) is taken as the Phosphate precursor. Aluminium Nitrate $\left(\mathrm{Al}\left(\mathrm{NO}_{3}\right) .9 \mathrm{H}_{2} \mathrm{O}\right.$, Merck $\left.\mathrm{GR}, 99 \%\right)$ is taken as the Alumina precursor. Ammonia is taken as the $\mathrm{pH}$ reagent. Double distilled water is used to obtain homogeneous solution. Magnesium Nitrate hexahydrate $\left(\mathrm{Mg}\left(\mathrm{NO}_{3}\right) .9 \mathrm{H}_{2} \mathrm{O}\right.$, Merck GR, $\left.99 \%\right)$ is taken as the Magnesium precursor. $\mathrm{NaOH}$ (Merck, purity $99 \%$ ) is taken as the $\mathrm{pH}$ reagent. Double distilled water is used to obtain homogeneous solution.

\section{Synthesis of nano $\mathrm{Ha}$ alumina and $\mathrm{Ha} / \mathrm{Mgo}$ composite}

The $0.05 \mathrm{M}$ of $\mathrm{Al}_{2} \mathrm{O}_{3}$ was prepared by adding $4.68 \mathrm{~g}$ of Aluminium Nitrate dissolved in $250 \mathrm{ml}$ de-ionized water. Then the ammonia solution ( $25 \%$ of ammonia) was added to increase the $\mathrm{pH}$ value to 11. Thereafter the prepared solution was allowed for overnight stirring and kept undisturbed for aging. In order to synthesize nanohydroxyapatite $5.9 \mathrm{~g}$ of Calcium Nitrate and $1.98 \mathrm{~g}$ of Diammonium Hydrogen Phosphate were taken in the hydrothermal vessel and mixed with de-ionized water with the molar ratio of 1:0.6 to maintain the $\mathrm{Ca} / \mathrm{P}$ ratio 1.67 which is the stoichiometric ratio of $\mathrm{HA}$. The $\mathrm{pH}$ of the above solution is increased to 9 by adding ammonia solution ( $25 \%$ of ammonia). The prepared Alumina solution was added drop by drop to the above solution. The vessel is placed in the oven of the hydrothermal instrument. The mixed solution was hydrothermally treated at $250^{\circ} \mathrm{C}$ for 5 hours. After 5 hours the autoclave is cooled to room temperature. Hydroxyapatite-Alumina nanocomposite is separated by filtration, washed a few times and kept in hot air oven at $60^{\circ} \mathrm{C}$. The dried composite is ground using mortar and pestle. Similarly, the $0.1 \mathrm{M}$ of $\mathrm{Mg}(\mathrm{OH})_{2}$ was prepared by adding $6.41 \mathrm{~g}$ of Magnesium Nitrate dissolved in $100 \mathrm{ml}$ de-ionized water. Then the $0.8 \mathrm{~g}$ of $\mathrm{NaOH}$ solution was prepared in $50 \mathrm{ml}$ de-ionized water. 
The $\mathrm{NaOH}$ solution added to increase the $\mathrm{pH}$ value to 11 . Thereafter the prepared solution was allowed for overnight stirring and kept undisturbed for aging. Then the experimental procedure is same for $\mathrm{HA} / \mathrm{MgO}$ nanocomposite was prepared at $250^{\circ} \mathrm{C}$.

\section{Results and discussion}

\section{XRD analysis}

The X-ray diffraction patterns of the powdered nanoparticles were recorded using XRD-1008 with $\mathrm{Cu}-\mathrm{K} \alpha$ radiation (1.54060 $\mathrm{A})$. XRD pattern for $\mathrm{HA} /$ Alumina and $\mathrm{HA} / \mathrm{MgO}$ Nanocomposite synthesised at $250^{\circ} \mathrm{C}$ shows clear reflections from the $\left(\begin{array}{lll}1 & 1 & 2\end{array}\right),\left(\begin{array}{lll}0 & 0 & 2\end{array}\right),\left(\begin{array}{lll}2 & 1 & 3\end{array}\right)$ and $(1$ $12),\left(\begin{array}{lll}0 & 0 & 2\end{array}\right)\left(\begin{array}{lll}2 & 1 & 1\end{array}\right),\left(\begin{array}{lll}3 & 1 & 0\end{array}\right)$ planes in the range $25^{\circ}-50^{\circ}$. The prepared samples show well-defined peaks which indicate high crystalline nature. All the diffraction peaks could be readily indexed with pure hexagonal phase (space group: $\mathrm{P} 6_{3} / \mathrm{m}(176)$ ) with lattice parameters of $\mathrm{a}=9.460 \AA$ and $\mathrm{c}=6.880 \AA$ which are in accordance with the JCPDS file card number \#821943. The average crystallite size of $\mathrm{HA} / \mathrm{MgO}$ and HA/Alumina samples synthesized as calculated by Scherrer's formula $(\mathrm{D}=\mathrm{k} \lambda / \beta \cos \theta)$ was $8.80 \mathrm{~nm}$ and $11.95 \mathrm{~nm}$ respectively. The value of lattice constants obtained are $\mathrm{a}=9.4740 \AA \hat{\mathrm{A}}, \mathrm{c}=6.8982 \AA$ and $\mathrm{a}=7.36779 \hat{\AA}, \mathrm{c}=3.6837 \hat{\mathrm{A}}$. The unit cell volume $(\mathrm{V})$ inferred is $1602.994 \AA^{3}$ and $1463.947 \AA^{3} .0 .0103$ And 0.0085 are the degree of crystallinity $\left(x_{C}(\%)\right)$. The $\left(\begin{array}{lll}0 & 0 & 2\end{array}\right)$ peak was chosen to calculate the average crystallite size, lattice parameters, unit cell volume and degree of crystallinity for HA. It is known that the preferential growth of apatite crystal is along the c-axis. ${ }^{4-7}$

The relationship between lattice constant (a \& c), Miller's indices $(\mathrm{h}, \mathrm{k}, \mathrm{l})$ and lattice spacing (d) is used to calculate lattice parameter values, expressed as,

$$
\frac{1}{d^{2}}=\frac{4}{3}\left(\frac{h^{2}+k+k^{2}}{a^{2}}\right)+\frac{l^{2}}{c^{2}}
$$

The volume $(\mathrm{V})$ of the hexagonal unit cell and the degree of crystallinity $\left(x_{C}\right)$ of the pure $n-H A$ and different $n-H A / S A$ composites are obtained using the equation, respectively, $\mathrm{V}=2.589$ $\mathrm{a}^{2} \mathrm{C}$ and

$$
\mathrm{X}_{\mathrm{c}}=\left(\frac{K_{A}}{\beta}\right)^{3}
$$

Where $\beta$ is the full-width at half maximum, $\times_{2}$ the degree of crystallinity, $\hat{\mathrm{E}}_{\mathrm{A}}$ the constant $(0.24)$ and a and $\mathrm{c}$ are lattice parameters (Figure 1A \& 1B). ${ }^{8}$

\section{FTIR analysis}

The characteristic peaks of HA/Alumina and $\mathrm{HA} / \mathrm{MgO}$ nanocomposites were examined by Fourier Transform Infrared Spectroscopy (FTIR). The pellet for FTIR measurements was prepared by mixing the sample ( $2 \mathrm{mg}$ ) with $200 \mathrm{mg}$ of IR grade $\mathrm{KBr}$. The mixed powder was pressed in a stainless steel pellet die for one minute at constant pressure to obtain a translucent disc. The absorption spectra were measured at $4000-400 \mathrm{~cm}^{-1}$ using SHIMADZU spectrometer, Japan.

Biological HA is usually Calcium deficient, it is always substituted with a carbonate. The most characteristic peaks in the FTIR spectra of synthesized $\mathrm{HA} /$ Alumina and $\mathrm{HA} / \mathrm{MgO}$ nanocomposites are $\mathrm{PO}_{4}^{3-}$, $\mathrm{OH}^{-}, \mathrm{CO}_{3}{ }^{2-}$ and $\mathrm{Al}^{3+}, \mathrm{Mg}^{2+}, \mathrm{CO}_{3}{ }^{2-}$ forms a strong peak at $1381.03 \mathrm{~cm}^{-}$ ${ }^{1}$ and $1396.43 \mathrm{~cm}^{-1}$. The broad peaks appeared at $1033.85 \mathrm{~cm}^{-1}$ and1018.41, 1072.42 $\mathrm{cm}^{-1}$ and 1080.41; indicate the presence of to the asymmetric stretching $\left(v_{3}\right)$ mode of vibrations because of the phosphate bonds. ${ }^{6,9}$ Weak peaks in the range $560-740 \mathrm{~cm}^{-1}$ and $555-$ $610 \mathrm{~cm}^{-1}$, are observed due to the presence of $\mathrm{Al}^{3+}$ ions and $\mathrm{Mg}^{2+}$ ions. ${ }^{6}$ The broad peak spread over the range between $3387-3435 \mathrm{~cm}^{-1}$ and $1635 \mathrm{~cm}^{-1}$ for HA/Alumina and $3109-3179 \mathrm{~cm}^{-1}$ and 1635.64 for HA/ $\mathrm{MgO}$ reveals the superposition of absorption because of the stretching mode of surface hydroxyl groups and adsorbed water molecules. ${ }^{10}$ $\mathrm{OH}^{-}$group forms strong and broad peaks in the range $3200-3600 \mathrm{~cm}^{-1}$ (Figure 2A \& 2B) (Table 1). ${ }^{11,12}$

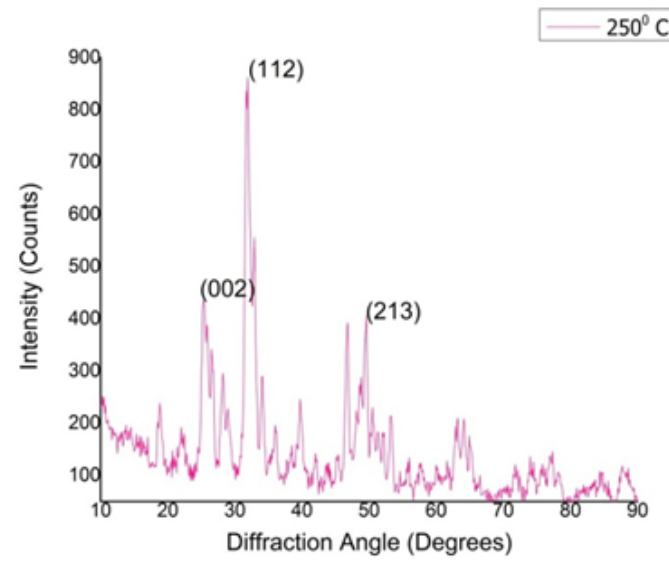

Figure IA XRD pattern of HA/Alumina nanocomposite at $250^{\circ} \mathrm{C}$.

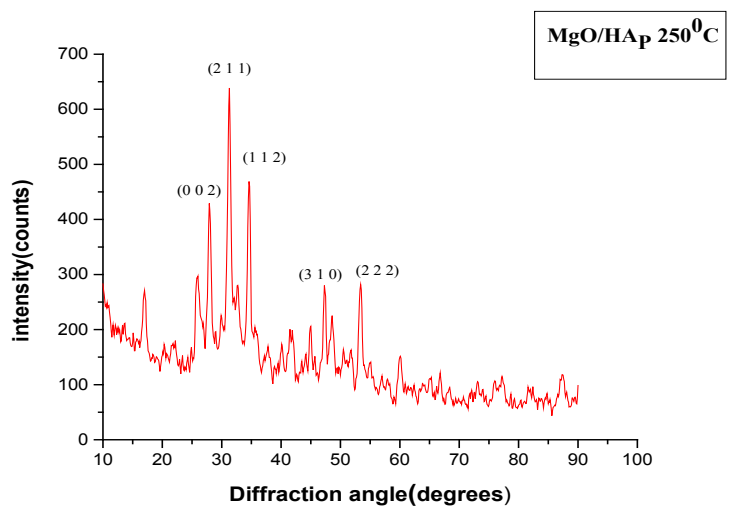

Figure IB XRD pattern of $\mathrm{HA} / \mathrm{MgO}$ nanocomposite at $250^{\circ} \mathrm{C}$.

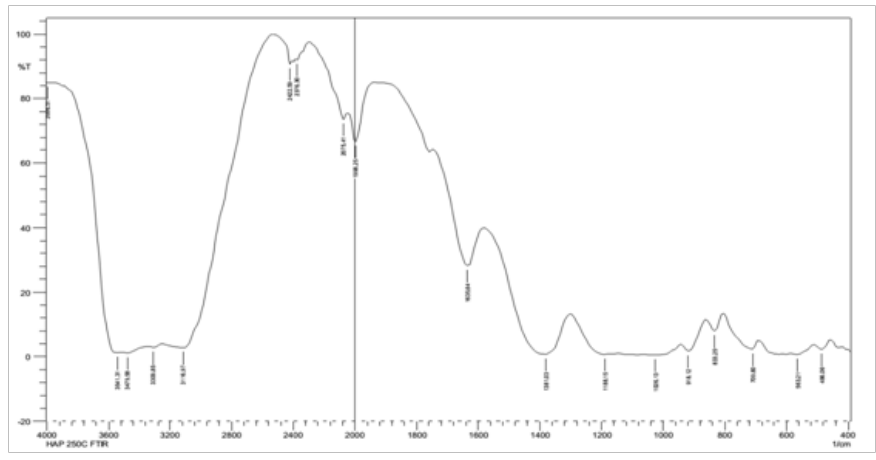

Figure 2A The FTIR spectra for HA/Alumina nanocomposite at $250^{\circ} \mathrm{C}$. 


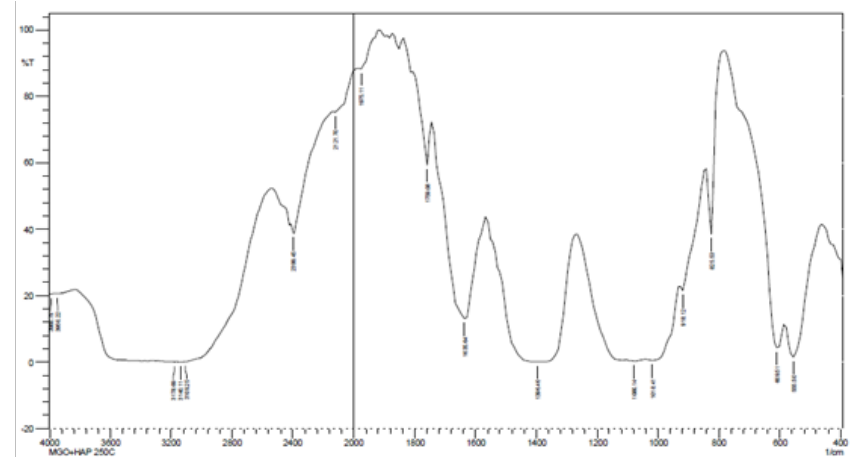

Figure 2B The FTIR spectra for $\mathrm{HA} / \mathrm{MgO}$ nanocomposite at $250^{\circ} \mathrm{C}$.

Table I Vibrational frequency

\begin{tabular}{|c|c|}
\hline $\begin{array}{l}\text { Vibrational } \\
\text { frequency }\left(\mathrm{Cm}^{-1}\right)\end{array}$ & Assignments \\
\hline \multicolumn{2}{|l|}{ HA/Alumina } \\
\hline 1381.03 & Carbonate band \\
\hline 1033.85, 1072.42 & v3asymmetric stretching of phosphate \\
\hline $560-740$ & Aluminium bands \\
\hline $3200-3600$ & $\begin{array}{l}\text { Stretching mode of surface hydroxyl Groups } \\
\text { and adsorbed water molecules }\end{array}$ \\
\hline \multicolumn{2}{|c|}{ HA/MgO nanocomposite } \\
\hline 1396.43 & Carbonate band \\
\hline $1018.41,1080.14$ & $v 3$ asymmetric stretching of phosphate \\
\hline $555-610$ & Aluminium bands \\
\hline $3100-3200$ & $\begin{array}{l}\text { Stretching mode of surface hydroxyl Groups } \\
\text { and adsorbed water molecules }\end{array}$ \\
\hline
\end{tabular}

\section{TEM analysis}

The particle size and morphology of the synthezised HA/Alumina $\mathrm{HA} / \mathrm{MgO}$ nanocomposite have been examined by TEM. The Figure $3 \mathrm{~A}-3 \mathrm{C}$ reveals the TEM images of $\mathrm{HA} /$ Alumina and $\mathrm{HA} / \mathrm{MgO}$ nanocomposite at $250^{\circ} \mathrm{C}$. The sample exhibits relatively uniform distribution with nanorod and nanocluster like morphology. ${ }^{9,13}$
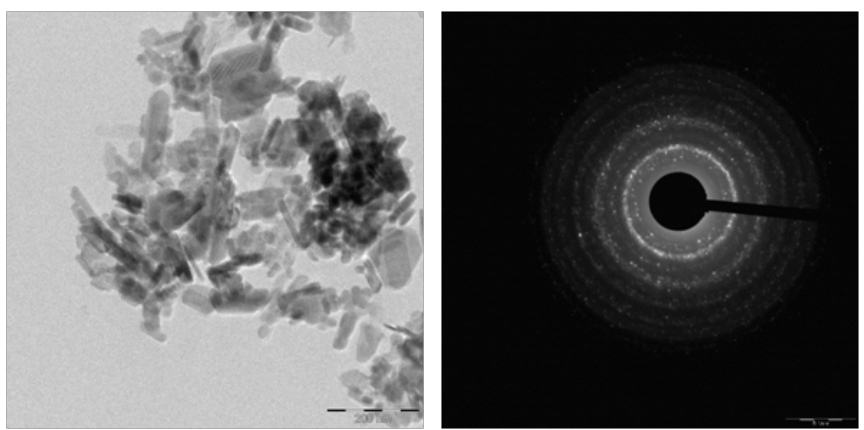

Figure 3A TEM image of HA/Alumina nanocomposite at $250^{\circ} \mathrm{C}$.

\section{Uv-visible spectrum analysis}

The UV-visible absorption spectra of the samples were recorded in the wavelength range of 200 to $800 \mathrm{~nm}$ using a Shimadzu UV
1700 UV spectrometer. The band gap energy was calculated by using Einstein formula $(E=h c / \lambda)$. Where $h$ is a Planck's constant $\left(6.626 \times 10^{-}\right.$ $\left.{ }^{34} \mathrm{~J}\right), \mathrm{c}$ is the velocity of light $\left(3 \times 10^{8} \mathrm{~m} / \mathrm{s}\right)$ and $\lambda$ be the wavelength of the sample recorded (Figure $4 \mathrm{~A} \& 4 \mathrm{~B}$ ).
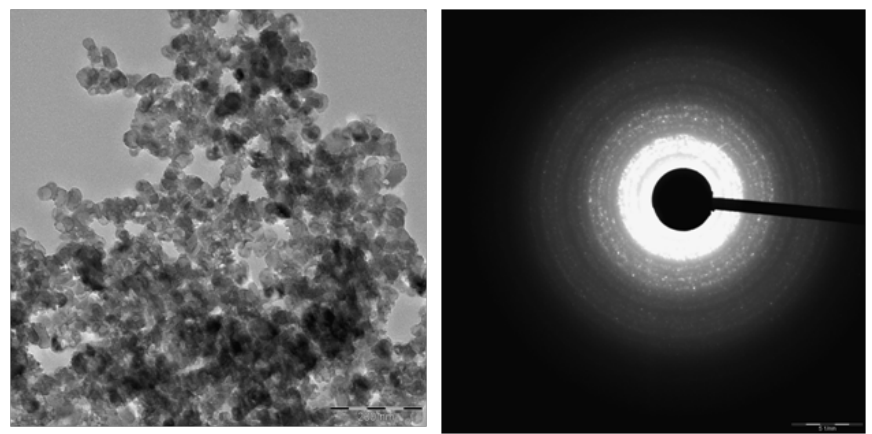

Figure 3B High resolution TEM image at $250^{\circ} \mathrm{C}$.3C) Polycrystalline diffraction pattern of $\mathrm{HA} / \mathrm{MgO}$ at $250^{\circ} \mathrm{C}$ recorded.

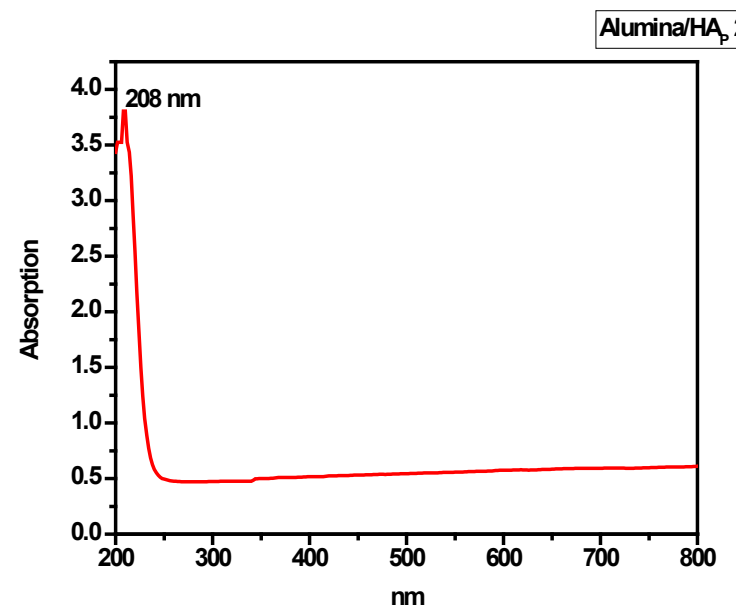

Figure 4A UV-VIS SPECTRUM of HA/Alumina nanocomposite at $250^{\circ} \mathrm{C}$.

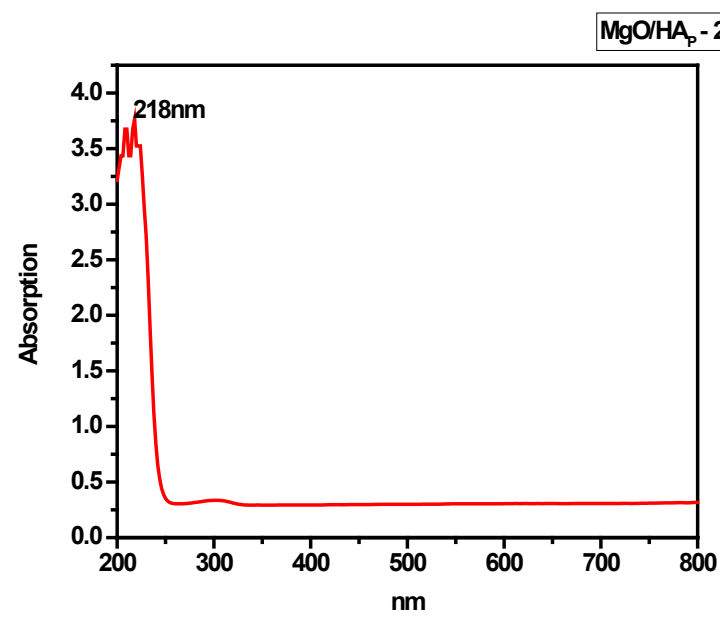

Figure 4B UV-VIS Spectrum of $\mathrm{HA} / \mathrm{MgO}$ nanocomposite at $250^{\circ} \mathrm{C}$.

UV-visible spectroscopy was used to characterize the optical absorption properties of $\mathrm{HA} /$ Alumina and $\mathrm{HA} / \mathrm{MgO}$ nanocomposites at $250^{\circ} \mathrm{C}$. We obtained the band gap to be $5.97 \mathrm{eV}$ for HA/Alumina at $250^{\circ} \mathrm{C}$ and $\mathrm{MgO} / \mathrm{HA}$ at $250^{\circ} \mathrm{C}$ as $5.689 \mathrm{eV}$ respectively. 


\section{Conclusion}

In this study, $\mathrm{HA} /$ Alumina and $\mathrm{HA} / \mathrm{MgO}$ nanocomposites were successfully prepared by using the hydrothermal method. The mechanisms of composite formation, crystallite size, crystallinity, morphology, were studied HA/Alumina and $\mathrm{HA} / \mathrm{MgO}$ nanocomposites. XRD and FTIR investigations showed an intermolecular interaction between $\mathrm{HA} /$ Alumina and $\mathrm{HA} / \mathrm{MgO}$. The formation of $\mathrm{HA}_{\mathrm{p}} /$ Alumina and $\mathrm{HA} / \mathrm{MgO}$ nanocomposites confirmed by FTIR, XRD and TEM analysis methods. The formation of $\mathrm{HA} /$ Alumina and $\mathrm{HA} / \mathrm{MgO}$ nanocomposites are polycrystalline in nature. It confirmed in TEM analysis. TEM images further ascertained that HA/Alumina was formed in a short nanorod shape and $\mathrm{HA} / \mathrm{MgO}$ nanocomposites show nanocluster like morphology. The FTIR measurement shows the appropriate vibrational spectra of HA/Alumina and $\mathrm{HA} / \mathrm{MgO}$ nanocomposites. The UV-VIS measurements show the band-gap of HA/Alumina and $\mathrm{HA} / \mathrm{MgO}$ nanocomposites. This study provides a platform for further research on the $\mathrm{HA} /$ Alumina and $\mathrm{HA} / \mathrm{MgO}$ nanocomposites for biomedical applications.

\section{Acknowledgements}

None.

\section{Conflict of interest}

The author declares no conflict of interest.

\section{References}

1. Kirkland NT, Birbilis N, Walker J, et al. In-vitro dissolution of magnesium-calcium binary alloys: clarifying the unique role of calcium additions in bioresorbable magnesium implant alloys. $J$ Biomed Mater Res B Appl Biomater. 2010;95(1):91-100.

2. Yang Shia, Min Qia, Yao Chenb, et al. MAO-DCPD composite coating on $\mathrm{Mg}$ alloy for degradable implant applications. Materials Letters. 2011;65(14):2201-2204
3. Fernandez-Garcia $M$, Wang $X$, Belver $C$, et al. Anatase-TiO Nanomaterials: Morphological/Size Dependence of the Crystallization and Phase Behavior Phenomena. J Phys Chem C. 2007;111(2):674-682.

4. Rajkumar M, Meenakshisundaram N, Rajendran V. Development of nanocomposites based on hydroxyapatite/sodium alginate: Synthesis and characterization. Materials Characterization. 2011;62(5):469-479.

5. Haque S, Rehman I, Darr JA. Synthesis and characterization of grafted nanohydroxyapatites using functionalized surface agents. Langmuir. 2007;23(12):6671-6676.

6. Hu R, Lin CJ, Shi HY. A novel ordered nano hydroxyapatite coating electrochemically deposited on titanium substrate. J Biomed Mater Res A. 2007;80(3):687-692.

7. Rajkumar M, Meenakshisundaram N, Rajendran V. Int J Eng Sci Technol. 2010;2(6):2437-2444

8. Rajkumar M, Kavitha K, Prabhu M, et al. Nanohydroxyapatitechitosan-gelatin polyelectrolyte complex with enhanced mechanical and bioactivity. Mater Sci Eng C Mater Biol Appl. 2013;33(6):3237-3244.

9. Milella E, Cosentino F, Licciull Ai, et al. Preparation and characterisation of titania/hydroxyapatite composite coatings obtained by sol-gel process. Biomaterials. 2001;22(11):1425-1431.

10. Varma RS, Saini RK, Dahiya R. Tetrahedron Lett. 1997;38:7823.

11. Su-Hee Lee, Hyoun-Ee Kim. J Am Ceram Soc. 2007;90(1):50-56.

12. Hae-Won Kim, Long-Hao Li, Young-Hag Koh. Sol-Gel Preparation and Properties of Fluoride-Substituted Hydroxyapatite Powders. J Am Ceram Soc. 2004;87(10):1939-1944.

13. Cava S, Tebcherani SM, Souza IA, et al. Structural characterization of phase transition of $\mathrm{Al}_{2} \mathrm{O}_{3}$ nanopowders obtained by polymeric precursor method. Materials Chemistry and Physics. 2007;103:394-399. 